\title{
Does Sport Science need counseling?
}

\author{
Martin Kopp ${ }^{1, *}$ \& Justin S. Lawley ${ }^{1}$ \\ 1 Department of Sport Science, University of Innsbruck, Innsbruck, Austria \\ * Corresponding author: Department of Sport Science, University of Innsbruck, Fürstenweg 185, 6020 Innsbruck, Austria \\ Tel: +4351245851 \\ E-Mail: martin.kopp@uibk.ac.at
}

\section{EDITORIAL}

\section{Article History:}

Published $4^{\text {th }}$ November 2019

Editor-in-Chief:

Martin Kopp

University of Innsbruck, Austria

\section{ABSTRACT}

Sports science is an emerging discipline in the field of science (Block, 2016). Traditionally sports science has been recognized as simply educating secondary school teachers in physical education. However, this notion has mostly passed as researchers within the field of sport and exercise sciences have contributed significantly to our understanding of the totality of the human condition. A good example as to the importance of modern day sport science is the large body of scientific evidence that regular and optimized physical activity can increase strength and endurance, substantially reduce the risk of diabetes, heart attack, stroke, cognitive decline and development of Alzheimer's disease, and improve quality of life over the entire life span, with little or no side effects. A notion that is now immortalized in the concept that "exercise is medicine" (Berryman, 2010).

In this context, some aspects of the modern day sports science department should be considered, in order not to jeopardize the great developments that have been made and future developments of the discipline.

Keywords:

sport science - development - perspectives

Citation:

Kopp, M. \& Lawley, J. S. (2019). Does Sport Science need counseling? Current Issues in Sport Science, 4:009. doi: 10.15203/CISS_2019.009.

\section{Self-esteem in sports science}

The question of whether self-esteem is worthwhile for a branch of science may seem absurd to some traditional sports scientists. The historical development of scientific contributions in competitive sport has led to a self-image of sports science that has probably been shaped by the internalisation of principles and motivational framework conditions from competitive sport. But the principles of achieving more (than others) in the sense of 'higher, faster, further' are potentially also approaches that can weaken a branch of science. By increasing the demand for so-called scientificness and comparability, research designs can slip into the unrealistic and thus lose ecological validity. An exclusive assessment of research achievements using quantitative criteria should also be critically questioned (Fang \& Casadevall, 2015). When it comes to performance of sports science, a set of rules should be laid down to determine which criteria are actually to be used to evaluate performance. Whether this is to be found exclusively in the number and ranking of scientific publications remains an important question for the future - a regular reflection of such performance criteria seems necessary in any case (Bollen, van de Sompel, Hagberg, \& Chute, 2009; Kurmis, 2003). Overall, on the basis of self-determination theory, it can be stated that control and comparison have a potential to damage motivation in the long run and can go hand in hand with a reduction in performance. In contrast, social conditions that support autonomous development can lead to optimal development and performance (Deci \& Ryan, 2000). A further question will be whether the quality of the graduates of the subject can make significant contributions in the various professional fields of sports science. This leaves the question to what extent the selfesteem of sports science as a branch of science is currently too strong in comparison with other disciplines on a performanceoriented basis, or whether there is already sufficient reflection and self-criticism in the development of one's own discipline. 
In our opinion, there is an essential need for counseling in this area for a constructive further development of the discipline of sports science, whereby the need for counseling is to be understood more in the observation and contact with other branches of science and the analysis of their developments (Schrecker, 2010).

\section{Relationship to the mother sciences and within the various sub-disciplines}

Perhaps one of the greatest strengths of sports science is its multidisciplinary approach to understanding life on Earth, especially in our connection and collaboration with the socalled mother sciences. Indeed, basic principles in physics, psychology, physiology and medicine are the cornerstones of well-founded research topics and teaching in sports science. In order to promote the professional identity and competence of sports scientists, future goals must be to further develop our curriculum and communicate that sports science graduates understand more than simply how to play sport. Indeed, graduates should have an in-depth scientific understanding of the mother sciences, but integrated into the performance, social and health benefits of performing sport and physical activity. Moreover, even if certain fields of activity should be linked to an education in sports science, this practical approach must be sharply separated from how university research and teaching should be conducted. There should be a skill-oriented approach that only reflects the quality of the scientist's teaching and research capacity and completely dissociates itself from the person's actual degrees. An essential step in this direction, as in many other countries, should be that graduate students from the mother sciences can complete doctoral degrees in sports science without the requirement to have studied sports science. In our opinion, there is no reason to believe that a physicist, clinical psychologist or medical doctor would not excel in biomechanics, sports psychology or physiological research. Indeed, many of histories previous and current thought leaders in sports and exercise science completed their graduate degree in the mother sciences. Based on personal experience, integration with the mother sciences is our greatest strength; not only to develop the area of sports science, but a two-way transfer of knowledge, exchange of ideas and technical expertise in order to answer important research questions. The call for further cooperation and integration of the mother sciences is thus an appeal for growth of the discipline of sports science.

The situation is similar with regard to acceptance between the various disciplines of sports science. The discussion as to which disciplines carry the most importance or are placed together under teaching or research themes takes place at many institutes and seems not to want to end. A rough distinction could be made between biomechanical/technical, physiological/medical and psychological/sociological disciplines in sports science. Although it remains open how, for example, the definition of training science, performance diagnostics, sports nutrition, epidemiology or the area of sports pedagogy is positioned, since those branches are inherently multidisciplinary, depending on the eye of the beholder, and can be discussed in the areas of biomechanical/technical, physiological/medical and psychological/sociological. In the recent past, sports pedagogy, in particular in German speaking areas, has increasingly experienced positioning problems, which are primarily due to the fact that many representatives of the discipline have not followed the general trend towards internationally visible publication activities. With regard to understanding between the subjects of sports science, it can only be called upon to establish as many fundamental disciplines as possible side-by-side with tolerance and mutual respect, whereby the resource-related deposit and strengthening of the three basic axes of biomechanics, physiology and psychology can, in the authors' view, form an essential overarching foundation for comprehensive research and teaching (Hatfield, 2008; Knudson, 2016). That said, sport science should see itself as the umbrella of all natural and social science sub-disciplines related to human movement/physical activity (Knudson, 2016).

\section{Internationalisation in research and teaching}

The discipline of sports science has developed somewhat differently in Anglo-American countries and German-speaking countries in recent decades. In Anglo-American sport science departments (aka Department of Kinesiology, School of Sports Health and Exercise Sciences, School of Human Movement and Nutrition Sciences etc. etc.) an early transition was made to develop the discipline by focusing hiring appointments and supporting faculty members that produced world-leading research outputs in international peer-reviewed journals (Knudson, 2016). This development in German-speaking areas took place only in about the past two decades. Another development can be observed in the field of teaching. AngloAmerican institutions have focused their curriculum on science (i.e. psychology and pedagogy, biochemistry and physiology, nutrition and metabolism, biomechanics, motor control and learning, business and economics, research methods and statistics, critical thinking, analysis of scientific literature, presentation and data dissemination skills etc.) over several decades, whereas in many German-speaking universities, sports (i.e. practical training and competence) still encompasses an essential foundation of the curricula. This trend is also represented in the admissions process whereby Anglo-American institutions typically rely on similar admission requirements as other scientific studies, primarily on secondary school grades in topics such as science (biology/chemistry/ physics), mathematics, and physical education. In many German-speaking areas, after completion of the Abitur, the only admission requirement is often the successful completion of sports specific motor skills and sports performance. Indeed, 
this concept continues alongside the scientific education throughout the bachelor and masters curriculum in many German-speaking institutions where students pass practical courses based on improving their own personal performance or achieving performance targets in a wide range of sports. In our opinion, given the amazing historical achievements of German-speaking academics, it is sad to imagine how many excellent scientists have been turned away from studying sports science and making important contributions to human health and performance simply because they could not climb a pole or rope in a given time or perform repeated basketball layups. Perhaps highlighting our own bias, but it is also unlikely that either of the authors could have passed the current standards at age 18 , yet we hope we have made and will continue to make important advancements in sports science.

Here it is worthwhile reflecting on the goal of this practical sport based approach. From a practical point of view, at least intuitively, it is preferable that a teacher of physical education, physical trainer or physiotherapist can themselves perform the sports or movement patterns to which they are advocating. But is there any evidence that despite passing the entrance exams and hundreds of taught hours in practical classes, that these individuals maintain their performance thru their careers? Can all 35 years old Austria physical education teachers still perform gymnastic routines, swim butterfly or perform 10 basketball layups? The jury is out and awaiting scientific investigation, but it is unlikely and thus limits the validity of demanding such competency. Would the students themselves and the population as a whole not benefit more from additional classes in presenting scientific data to the general public, correct nutritional requirements for children engaged in sports or exercise and exercise prescriptions to reduce the risk of heart failure, for example?

We suggest that in a modern fiscally conservative university structure and highly competitive international jobs market, placing so much emphasis on personal motoric performance and sports that are not required for direct employment is outdated and likely not optimal for student success in the world of work and the visibility and scientific impact of a sports science department and University at large. That being said, our aim is not to throw the baby out with the bathwater and suggest all practical lessons are without merit. Instead, we simply suggest that practical classes should be focused on the specific needs of society and directed towards excellent education in how to correctly teach the theory and practice of sports contained within most secondary schools current curriculum or within the framework of training interventions or rehabilitation in the case of health disorders. If students wish to further their employment possibilities by attaining additional qualifications in didactics of sports such as ultimate frisbee, they can always do so in their own time and at their own cost and not that of the taxpayer.

\section{Digitalization}

The question of the extent to which sports science is already sufficiently concerned with digitalization must be answered on several levels. In the field of simulation and related research, sports science seems to be very innovative and can be classified as leading for certain developments. In the field of practical applications resulting from digitalization, there seems to be a need for further development. Particularly in the training of teachers, the potential of digitization must be understood as meaning that in the future practical training in the sense of the teachers' own mastery of certain sports and movement forms may take a back seat due to the completely new and mobile demonstration possibilities. As a result, even more attention could be paid to other elements of physical education teaching, especially in the training of health psychological competences for future teachers. Psychological-pedagogical research in sports science, in particular, could provide important inputs in this area for the future. Digital instruction and feedback systems should also be referred to in the area of training possibilities, but many innovations already seem to be taking place here. Overall, it is not easy to predict how technological inventions will change our teaching and research but at least we have to go with Finkenberg (2008), who wrote:

"What is obvious is that change takes place, and we must admit that we change with time." (Finkenberg, 2008, p 442)

\section{Meaningful Ideas - Summarized}

A self-critical work on the development of the discipline sports science through increased interaction with other scientific disciplines could favour the further establishment - given the acceptance of the discipline to the extent that strategies for self-justification can be abandoned.

Tolerance and cooperation with the respective fields of the mother sciences and within the various subjects of sports science is to be regarded as an essential basis for the further development and success of the subject (Knudson, 2019).

The authors believe that strengthening the three basic axes of biomechanics, physiology and psychology can form an essential foundation for comprehensive research and teaching at sports science institutes.

A commitment to the publication and discourse of knowledge gained in international journals should be a matter of course for all disciplines of sports science.

From the authors' point of view, a trend reversal should take place to the effect that the teaching of sport and exercise in various contexts should come to the fore, independent of the students' own performance limits.

In line with this, the potential of digitalization could be used in the university training of teachers, above all, in such a way that the teachers' own mastery of various forms of sport and movement takes a back seat to the completely new and mobile demonstration possibilities. 


\section{Funding}

The authors have no funding or support to report.

\section{Competing Interests}

Martin Kopp's role for CISS is Editor-in-Chief (2016-2020) and Founding Editor (2015).

\section{Data Availability Statement}

All relevant data are within the paper.

\section{References}

Berryman, J. W. (2010). Exercise is medicine: a historical perspective. Current sports medicine reports, 9, 195-201.

Block, B. A. (2016). The Professoriate and the Future of Higher Education Kinesiology: Quest, 68(3), 229-239. doi: 10.1080/00336297.2016.1180307

Bollen, J., van de Sompel, H., Hagberg, A., \& Chute, R. (2009). A principal component analysis of 39 scientific impact measures. PloS one, 4, e6022.

Deci, E. L., \& Ryan, R. M. (2000). The" what" and" why" of goal pursuits: Human needs and the self-determination of behavior. Psychological inquiry, 11, 227-268.

Fang, F. C., \& Casadevall, A. (2015). Competitive Science: Is Competition Ruining Science? Infection and Immunity, 83(4), 1229-1233. doi: 10.1128/IAI.02939-14

Finkenberg, M. E. (2008). Future Choices, Future Trends in Technology in Kinesiology and Physical Education. Quest, 60(4), 433-442. doi: 10.1080/00336297.2008.10483590

Hatfield, B. D. (2008). E Pluribus Unum-from DNA to social systems: Understanding physical activity through an integrated perspective. Quest, 60, 154-177.

Knudson, D. (2016). Future Trends in the Kinesiology Sciences. Quest, 68(3), 348-360. doi: 10.1080/00336297.2016.1184171

Knudson, D. (2019). Kinesiology's Tower of Babel: Advancing the Field with Consistent Nomenclature. Quest, 71(1), 4250. doi: 10.1080/00336297.2018.1492427

Kurmis, A. P. (2003). Understanding the limitations of the journal impact factor. Journal of Bone \& Joint Surgery, 85, 2449-2454.

Schrecker, E. (2010). The lost soul of higher education: Corporatization, the assault on academic freedom, and the end of the American university. The New Press. 